\title{
The Construction of the Civil Delivery Mechanism under the Principle of Due Process of Law--An Empirical Analysis Based on Civil Delivery of Xuzhou Court
}

\author{
Donghua Sun \\ Xuzhou Municipal People's Government Legal Office. Xuzhou. China. \\ 893694262@qq.com
}

\begin{abstract}
As an essential part of the production chain of the case, it is indispensable for it. It connects every process and records every call of the producer of the case. This paper investigates and analyzes the status quo of alienation of the civil litigation delivery mechanism through questionnaires, analyzes and examines the causes of alienation, and then initiates the establishment of court service organizations, expands the scope of collectors, and introduces competition mechanisms under the principle of due process of law. Thoughts on pushing the mail delivery to the society, standardizing the scope of the announcement, broadening the announcement medium, accelerating the construction of the platform, and making good use of the electronic delivery mechanism such as electronic delivery.
\end{abstract}

Keywords: Delivered; due process of law; construction approach; empirical analysis.

\section{Introduction}

As an essential part of the production chain of the case, it is indispensable for it. It connects every process and records every call of the producer of the case. This paper investigates and analyzes the status quo of alienation of the civil litigation delivery mechanism through the questionnaires, analyzes and examines the causes of alienation, and then initiates the establishment of court service organizations, expands the scope of collectors, and introduces competition mechanisms under the principle of due process of law. Thoughts on pushing the mail delivery to the society, standardizing The scope of the announcement, broadening the announcement medium, accelerating the construction of the platform, and making good use of the electronic delivery mechanism such as electronic delivery. [1-3]

Table 1. Overview of the personnel involved in the survey

\begin{tabular}{|c|c|}
\hline Personnel & : A total of 209 people, including 188 grassroots courts and 21 intermediate courts \\
\hline Duties: & 110 judges, 58 clerk, 40 assistant judges, 1 other staff \\
\hline Department: & The first-level court, the court, the civil court, the second court \\
\hline $\begin{array}{c}\text { Court } \\
\text { Overview: }\end{array}$ & $\begin{array}{l}\text { The grassroots courts are located in Xuzhou City and the county, respectively, with } \\
\text { more than } 200 \text { cases closed per capita; } \\
\text { The Intermediate Court is located in Xuzhou City, with more than } 150 \text { cases closed per } \\
\text { capita. }\end{array}$ \\
\hline
\end{tabular}

\section{Establish a Delivery Organization to Expand the Scope of the Collection}

(1) Direct delivery by a special person. A full-time delivery team consisting of judicial police, assistant judges and clerk will be set up within the court to deliver the work in a unified manner and to deliver the classification. If it is classified according to the type of service document, the complexity of the litigation procedure, the different stages of the same procedure, the address of the person to be served, the delivery of other cases, etc., the assessment is at different levels, considering different Delivery methods and delivery requirements ranging from lenient. [4]

(2) Expanding the scope of the collection. According to different requirements of rights and obligations, it is divided into two types of collectors: 
1. Obligated collectors. The scope of the duty collector can be extended to the co-residents and employees with considerable recognition ability on the original statutory basis, and the legal person is extended to other discerning staff in the office;

2. Voluntary collection. Emphasis on voluntary, with the right to choose whether to sign, for which it is not applicable to lien, in addition to the obligor, the units and individuals closely connected with the recipient, such as grassroots organizations, work units, residential properties, relatives Neighbors, colleagues, friends, etc., with their consent, will submit the litigation documents to their signatures, unless the parties are parties to each other.

(3) Applying mandatory measures. For those who are maliciously evaded or obstructed to be served, such as malicious rejection, false address, evasion, etc., they should also bear corresponding legal responsibilities, and take compulsory measures against the responsible person to impair civil lawsuits: fines and even detention, etc. The civil delivery work went smoothly.

Table 2. The court directly served the participants

\begin{tabular}{|c|c|c|c|c|c|c|}
\hline & Judge & $\begin{array}{c}\text { assistant } \\
\text { judge }\end{array}$ & clerk & $\begin{array}{c}\text { Retired } \\
\text { staff }\end{array}$ & Marshal & $\begin{array}{c}\text { Full-time direct } \\
\text { delivery }\end{array}$ \\
\hline $\begin{array}{c}\text { Number of } \\
\text { people }\end{array}$ & 182 & 170 & 202 & 6 & 52 & 35 \\
\hline percentage & $87 \%$ & $81 \%$ & $97 \%$ & $3 \%$ & $25 \%$ & $17 \%$ \\
\hline
\end{tabular}

\section{Improve the Competition Mechanism, Mail Delivery to the Community}

(1) Strengthen regular consultations. It is necessary to establish a regular communication and coordination mechanism with the postal department, and timely report the problems in the postal delivery to the postal department, jointly study and improve the work measures, timely solve the new problems in practice, and urge the establishment of a standardized delivery mechanism. Strengthen training for postal delivery personnel, establish qualification assessment, enhance their sense of mission, standardize the delivery process, and improve delivery efficiency.

(2) Standard address confirmation. The courts at all levels shall have a uniform scale for the validity of the address confirmation, strengthen the judicial propaganda and interpretation, and return the returned address after the address confirmed by the address confirmation, or return it after the second delivery, and clarify the responsibility and risk commitment of the party. Find a balance between the rights and obligations of the court and the parties, avoid the transfer of the risk of delivery to the courts and judges, and cause the parties to have unwarranted petitions or visits due to service problems, affecting the credibility of the judiciary.

(3) Introducing social competition. Consider introducing social competition, pushing the mail delivery to the society, and trying to hire an outsourcing agency for delivery. In fact, the "court copy" business of the mailing agency is also a kind of employment, but not for the full sense of employment, the postal agency does not bear the responsibility for the effect of delivery. And let the outsourcing organization take responsibility for the responsibility of delivery documents, should be employed through open bidding, use its professional advantages and market competition awareness, reduce costs and improve efficiency.

\section{The Scope of the Normative Announcement, Broaden the Announcement Medium}

The delivery of the announcement is a typical presumptive delivery. The person to be served is often unaware of the facts of the complaint. Therefore, the delivery of the announcement should be cautious, and the form and release of the announcement should be strictly regulated.

(1) The pre-conditions for the specification announcement. The handling procedures for the delivery of the specification announcement. In order to determine that the whereabouts of the person to be served is unknown, in addition to the immediate family members of the person to be served or 
the documents or transcripts of the person who is closer to the person to be served, there shall be a circumstantial certificate from the local public security organ or the grassroots mass organization. The materials are appropriate; at the same time, it is necessary to improve the delivery transcripts of the announcement. The immediate family member of the person to be served or the person close to the person to be served should be investigated at the address or address of the addressee of the addressee to find out the recent situation of the person to be served and other contact information, and ask if the delivery can be delivered. If the explanation cannot be delivered, the court will serve the notice in accordance with the provisions and produce the corresponding legal consequences, and record the situation in the volume. After that, the announcement can be applied.

(2) Applying flexible announcement methods. For different groups, different announcement delivery methods should be adopted, and announcements should be issued in sub-category and subregional modes to maximize the protection of the litigant's litigation rights. For example, for the reality that farmers rarely read newspapers, the author believes that a better way is to post the announcement directly on the address of the addressee of the person to be served, the place of residence registration, and the population surrounding the residence, and record or record the postings; The person who is living in the city can publish an announcement in a newspaper with a large circulation in the place where the person is served, and try to increase the possibility that the person to be delivered can actually read the contents of the announcement.

(3) Select an effective announcement medium. According to the common sense and experience of life, combined with the principle of probability of statistics, the announcement is published on the media most likely to be contacted by the addressee, that is, it is published on the media where the address of the addressee is more. The most effective and direct way to protect the rights of litigants; in addition to the announcements and newspaper announcements stipulated in the Civil Procedure Law, it can be extended to the TV stations, radio stations, and networks where the addressee is located. Wait for the mass media to let the recipients know the contents of the announcement as much as possible so that they can participate in the lawsuit on time.

\section{Accelerate Platform Construction and Make Good Use of Electronic Delivery}

Table 3. Electronically delivered medium

\begin{tabular}{|c|c|c|c|c|}
\hline & fax & Email & Instant messaging tools such as We Chat and QQ & SMS \\
\hline Number of people & 110 & 161 & 136 & 182 \\
\hline percentage & $53 \%$ & $77 \%$ & $65 \%$ & $87 \%$ \\
\hline
\end{tabular}

(1) Building a platform. Try to use a unified electronic delivery platform, email address, fax number, telephone number, and instant messaging software number (QQ number, We Chat public number, etc.) that is open to the whole society to enhance the credibility of electronic delivery. However, it is necessary to use the encryption technology to fix the content of the electronic delivery. It is not allowed to modify and delete it without due process, so as to ensure the fairness and objectivity of the electronic delivery procedure, and also protect the privacy of the litigant data. In addition to technical problems, operational problems may also create a number of loopholes in the program, which requires the court to use higher-end technical means to eliminate hidden dangers, to ensure the safety and reliability of the electronic delivery process, so that the proceedings can proceed smoothly.

(2) Classification and promotion. Taking into account the technical and equipment requirements of electronic delivery, we should first strengthen judicial propaganda and select pilot units for orderly promotion. For the general parties, it is necessary to consider the factors such as age, education level and economic status, and ask the parties to accurately fill in the electronic delivery address confirmation letter to ensure the parties' right to know about the electronic delivery and its legal consequences. . The contents of the electronic delivery shall be mainly notice instruments that do not directly involve the disposition of their rights. For those who are not good at using the Internet or 
unable to use the Internet due to economic restrictions, it is not appropriate to apply electronic delivery, so as not to be counterproductive and increase the burden on the parties.

(3) Confirmation of receipt. The electronic delivery is based on the principle of confirmation, which can be regarded as a success if it is acknowledged by the person to be acknowledged. The civil procedure should be people-oriented, and a variety of electronic delivery methods can be flexibly combined. Before delivery, the relevant situation can be verified by telephone or by using instant messaging software. After delivery, you can request a reply to confirm whether it is received or not. Recording or related electronic data is saved as a basis for delivery. According to the "undeniable" [5] mechanism in the field of e-commerce, the court may also require neutral third-party service providers to provide data records and electronically-delivered content backups when the recipient is denied the receipt. , to prove that the person has been received.

In order to have a normal response after each call, in the place where the legal rules are not enough to cover, to legitimately pursue the legitimate interests, this is the only way to achieve the "rule of law." Due to the hasty writing of the article, the depth has not yet touched the roots, and the breadth is not as good as the end of the service. The views are only for investigation and ideas. However, I have changed my mind and believe that every effort we make is a smart relay. It is a quantitative change that is enough to trigger the qualitative change of reform. It is also slightly gratifying.

\section{References}

[1]. Song Chow, the practical application of electronic justice and institutional collision. Journal of China University of Political Science and Law [J], 2011 (1 :): 33.

[2]. Xin Hua, Civil Litigation Law of the Federal Republic of Germany. Law Press, 2014.

[3]. Taiwan Civil Procedure Law, China Civil and Commercial Law Network, visited on May 10, 2018.

[4]. Professionalism formed by professionalization can effectively improve delivery responsibility and delivery results.

[5]. Song Lining. Norms and Improvement: Research on the Electronic Delivery System of the New Civil Procedure Law. Legal System and Society [J], 2014(1): 20. 